\title{
QR based management system for plants shopping center
}

\author{
Saja Nasir1, Salih Mahdy Al-Qaraawi², Muayad Sadik Croock ${ }^{3}$ \\ ${ }^{1}$ Iraqi Commission for Computers and Informatics, Institute of Informatics for Postgraduate Studies, Iraq \\ ${ }^{2}$ Control and Systems Engineering Department, University of Technology, Iraq \\ ${ }^{3}$ Computer Engineering Department, University of Technology, Iraq
}

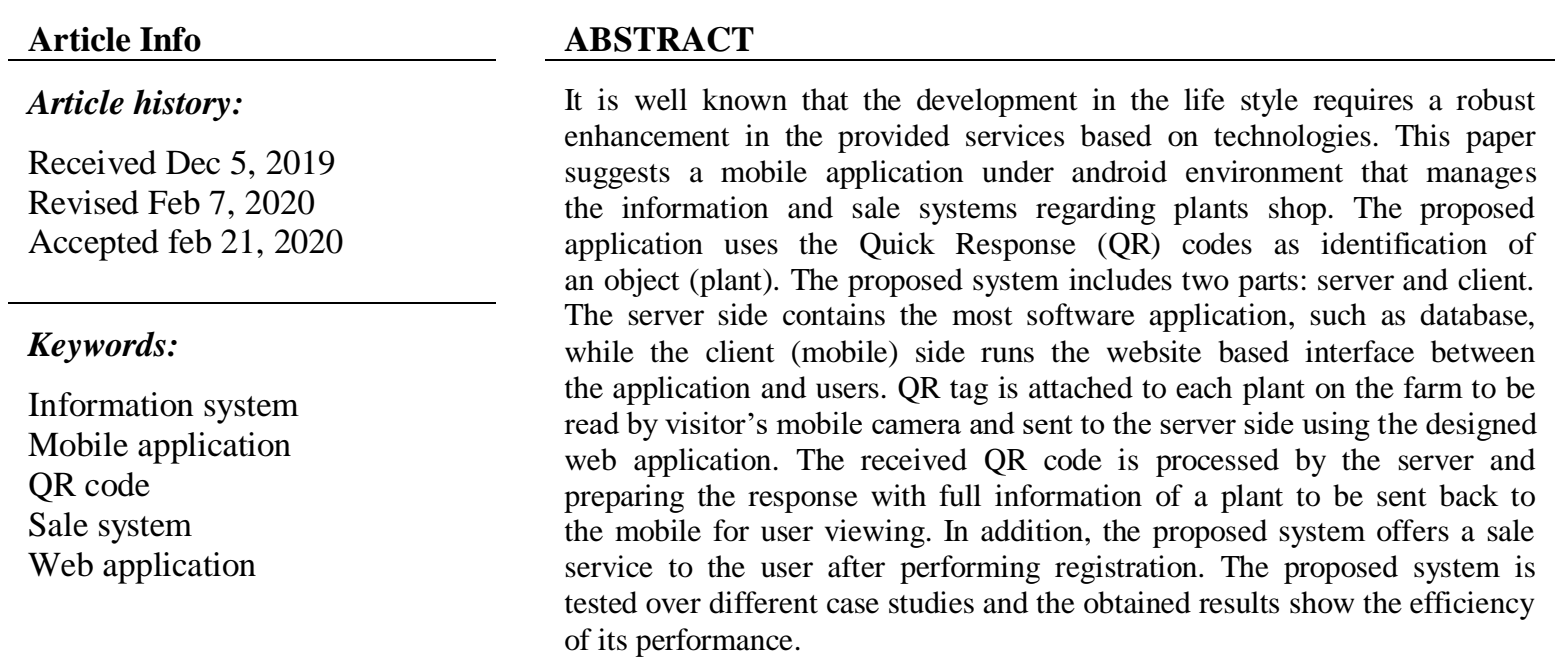

Copyright $\odot 2020$ Institute of Advanced Engineering and Science. All rights reserved.

\section{Corresponding Author:}

Muayad Sadik Croock,

Department of Computer Engineering,

University of Technology, Baghdad, Iraq.

Email:120102@uotechnology.edu.iq

\section{INTRODUCTION}

The Quick Response (QR) code is a type of Barcode matrix (or two dimensional Barcode). It was developed by the Japanese corporation (Denso Wave Incorporation)[1]. The popularity of QR is increased as it is shown in more urban environment places and QR codes need no licenses[2]. One of the important issue is appeared when users visit a plant shop who need a guide person to provide more detailed information about the plants, such as the price of the plants, the place of origin, the right soil, the right climatic conditions, the methods of prevention of pests infesting the plants...etc[3]. Sometimes in the crowded time, it is difficult to provide a guide for each customer as the institution needs a large number of workers as guide and thus increase the payment for workers[4]. Therefore, a QR based technique is used to design a system where the visitors can be easily guided on the shop without a guided person. Therefore, the proposed system can decrease the workers as much as possible, where smartphones and its applications were exploited for this purpose [5]. The smart mobile phone is one of the most dependable partners to users rather than any other device. So, the visitors can retrieve information quickly about the particular plants[6]. In this paper, a plant information and management system is proposed. The proposed system offers full information about the objects (plants) inside a shop. In addition, it manages the sale side after registering the users. The proposed system contains two sides: server and client. The server side includes the main software and database of plant's information. The client side is represented by mobile application under Android environment. Moreover, the proposed system provides a web application for managing its functions in an easy way for users. 


\section{LITERATURE REVIEW}

In the last few years, the information system based on QR codes has been considered in terms of techniques and applications. This section focuses on the related work survey about mobile applications. In [3], the authors presented an application that used QR codes to share laboratory results. The proposal was aimed to exchange data between the patient and the laboratory and between the patient and the electronic health records. The authors used the Advanced Encryption Standard to provide security for the data contained within the QR code. In this work, a mobile application-electronic glasses (eGlasses) was used to process data in graphical patterns, while the mobile phone was used as an emulator for electronic glasses. Different techniques were used for obtaining the satisfied results. In [5], the author suggested an attendance system based on the QR code, where the QR code is displayed to students at the start of the lecture. When the student came to a class, he confirmed his presence by reading the QR code displayed on the screen by using the student's mobile phone. Students also used their smart mobile phones to register to the classroom rather than of a professor's smart mobile phone or other QR reading device. The proposed system relied on GPS to detect a student who is trying to cheat in coming to class, in addition to take a picture of the face of the student at the same moment to make sure that he is the same student and in the same class. The offered system consists of two models: mobile units for clients and server for save and retrieve information.

In [7], a medical management system have introduced. E-Health systems are now able to provide healthcare at anywhere and anytime. The offered system was a reminder for medication intake where it tracked and managed all prescribed medications to prevent errors in taking the drug in terms of time or dose. Alerts for this proposed system were either acoustic, visual or vibratory, so the user of the application was aware of when and how much medicine was taken. The application allowed users to register the drug in the application by reading the QR that poster the medicine tray and read these codes by the user's camera that included in his smartphone. The main purpose of this application was to prevent errors in taking the medication by following and administering the prescribed medication to the patient. The medication is registered in the system either by reading QR or by manually entering it into the system. In [8], the authors introduced a system based on the Android system included in smartphones to identify objects based on reading QR codes. The system was designed to facilitate the identification of different elements. The offered system consisted of a database, web services working as an intermediary to access the database and the Android application for the user's phone or tablet. In [9], a new method to digitize academic transcripts, i.e. student's scores sheet was presented. The authors used a digital format that was included in the QR code that encode in the student's own scores sheet so cannot retrieve the data from unauthorized persons. In the other word, the digital information contained in the QR code cannot be easily decrypted and retrieved, only by using the system's web application. Which can upload the web site of system on a hosting site. This system can be utilized for universities.

In [10] and [11], the authors have introduced a shopping and entertainment system that uses QR codes. The system exploits Android apps, QR codes and a local network. A QR code was included for each object for sale. Each user can install the purposed application on the mobile phone and can use the smartphone camera to read the attached QR code on each item. So, the request was sending to the network then to the server for processing the request and sent the results to the user. Items that the user wants to buy are listed on the shopping list, the proposed system automatically updates the shopping list. In [12], an application for student identity using a QR code was implemented. On the student's identity, a QR code was attached. The student's personal information could be obtained by scanning the QR code included in the student's identity, by downloading and installing the QR code reader on the smartphone of the user. The data and records are collected in a Microsoft SQL Server management studio database, the data can be erased and recovered simply and speedily.

In [13], the authors suggested an application that helps users to get full details of public buses such as: displaying route the bus can take on the map, pay by scanning the QR code, the direct location of the bus... etc. They presented the outcomes of this system and the level of users' approval of all the functions afforded by this system. The system was tested using the Black Box method by arranging the project objectives. The results were positive as expected which was implemented correctly. In [14]a model for organizing legal information was proposed by including QR codes in the models. The proposed application provided generating and reading QR codes in addition to qualitative research regarding barriers and obstacles, for quick access to legal information when needed in legal academia. The information was saved in a database for classification and access to legal information when required. In the author's questionnaire for the proposed application, legal practitioners have shown particular interest in using QR codes to access and retrieve the legal information that wanted to obtain. 


\section{THE PROPOSED SYSTEM}

The proposed system is designed to perform information providing system for plants as well as managing the sale issues. The proposed system consists of the following subsections:

\subsection{System structure}

Figure 1 demonstrates the general structure of the proposed system in terms of hardware needed for connecting devices and how to link the client's smartphone and access points (routers) is executed by Wi-Fi communication technique. The connection between routers and main server is done via the wireless technique. It is shown that the request is started from the mobile application (client) to be passed to the server for processing and response. In addition, it supports the information exchange between the server and client. The system is based on QR code as identification of each plant in the farm.

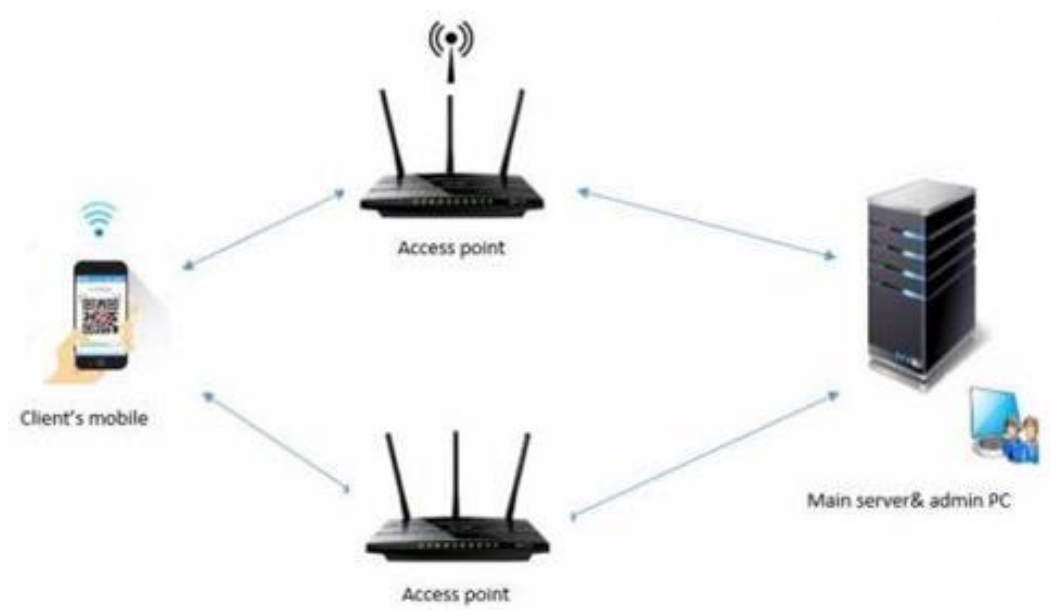

Figure 1. The proposed system hardware

\subsection{System network}

System network depends on some important parts:

a) Main server: in this proposed system, a computer is utilized as main server via installing AppServ software. This server includes entire information about plants inside the farm, customers' accounts (IDs), system administrators accounts, movement of each visitor at the shop like: The purchased plant name, price of plant, number of plants of the same type, total price, ID of the customer who purchased the plant, purchased date and time, etc. This information is stored in database tables using MySQL database are a package embedded in AppServ. The server also saves all system pages that are needed by system admin to insert, delete or update plants in the database. In addition to that, the webpages are used by the mobile phone application to send or retrieve data between the server and client's mobile phone by converting it to JSON format. These pages programmed by using PHP programing language.

b) Routers device: in the proposed system, the TP-LINK router is used to expand network access and enable access to the database in the main server at any place on the farm by the client's mobile phone to achieve information requested.

\subsection{The proposed algorithm}

Figure 2 illustrates the flowchart of the proposed algorithm used to manage the proposed system. The mobile phone application is designed by using android studio 3.4.1 IDE, and java programing language. The proposed mobile phone application adopted the proposed algorithm that consists of easy-to-use interactive interfaces and services the customer needs at the shop. The proposed algorithm performs the following steps:

a) Connecting to the available Wi-Fi network: when the user enters to the shop, the customer can connect to the adopted network by scan QR codes for shop's Wi-Fi access.

b) Choosing the available language: the user can select one of the language options (English, Arabic or French).

c) Reading QR signs: for every single plant there is a special QR code. The designed mobile application is equipped with a button for scan QR to read that information embedded in the QR code, and decode it. 
The information obtained from the QR code is sent to the shop's server. The server responses to the request by sending the relevant information to the customer mobile phone application to display requested information on his phone screen.

d) Get more information: when the server responses to the request introduced by the customer, only brief information about plants is retrieved. More Details button or Reload button is appeared for rather actions. If the customer is interested in showing plant details, he presses on More Details. If the customer wants to display another plant information he must press on the Reload button.

e) Buy plants: if the visitor intends to buy an item (plant), he presses on the BUY button in the proposed mobile phone application. The customer's account must be entered to the system if the customer has an account in that system. Otherwise, he can make a registration in the system. In registration process the required information are: customer name, password, customer Email, bank name, bank account, and MAC address. MAC address for smart mobile phone can be obtained by the system automatically when the customer presses on register button so to prevent repeated accounts. After the login process, the costumer can choose the sapling's count. The proposed application can compute the price of the total number of the selected plants. This application provides optional delivery service optionally depending on customer desire. In the delivery option, the customer address must be entered to be sent to the destination.

f) Items Selection (memorized) and Sale: when the customer wants to buy more than one sapling, it can be added to the cart by the press on the CART icon in the application bar. The costumer can also delete the unwanted items, while the visitor scan QR code for plant and obtain the information from server. At the end, the customer can display all selected items list with the total price for plants.

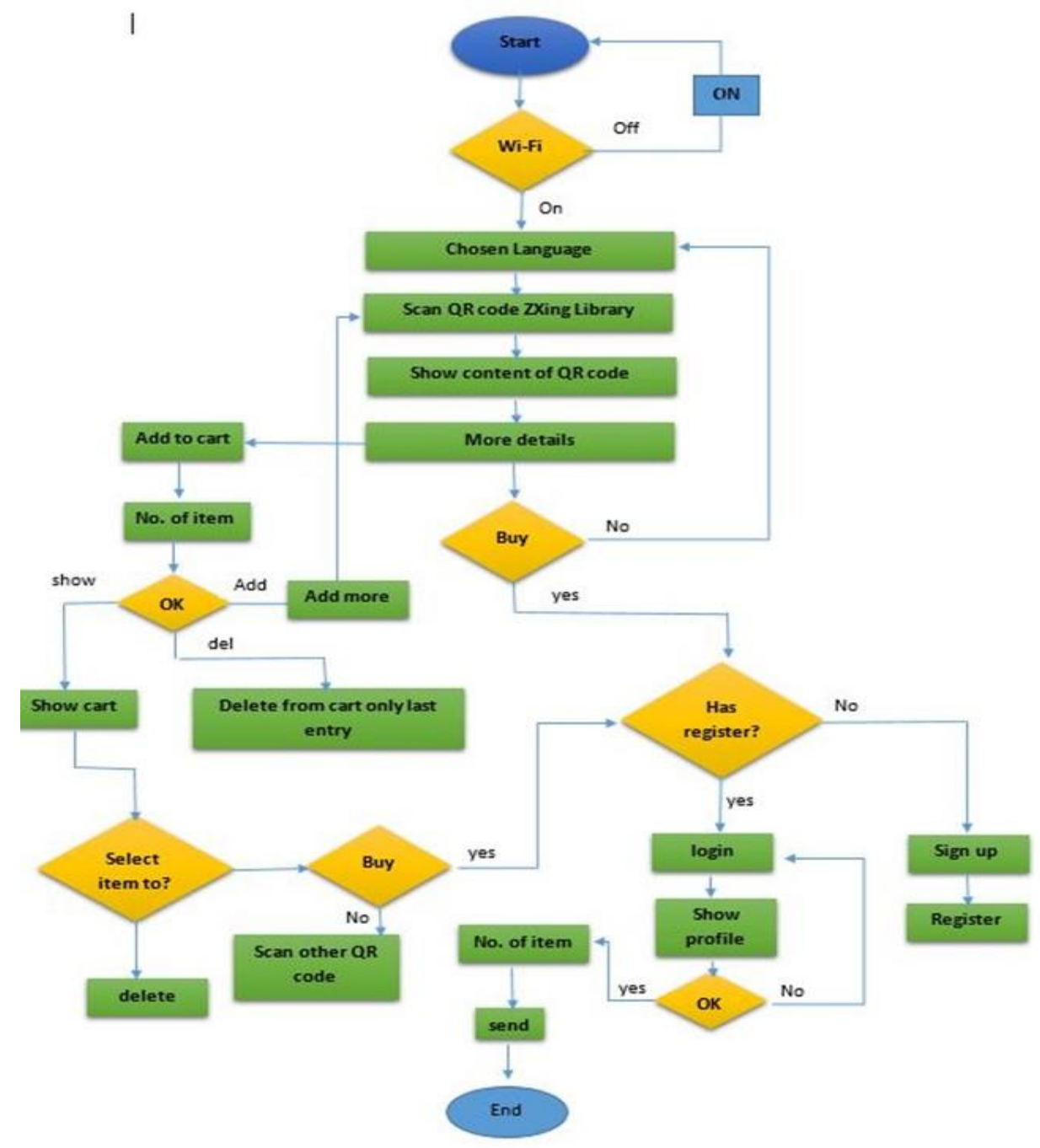

Figure 2. Flowchart of the proposed algorithm 


\subsection{QR codes for connection Wi-Fi}

In this step, signs of QR codes are attached to all farm entrances for connection by Wi-Fi. The username and password of the farm network are encrypted within the QR code [15]. When the customer enters the farm, the user scans the $\mathrm{QR}$ code. The costumer is immediately connected to the farm network. The QR code is produced by visiting a free website that supplies a QR code service to login to the Wi-Fi network and that QR code can be downloaded as a JPG image file [16]. Figure 3 shows the encryption of the shop's local network name and password in a QR code.
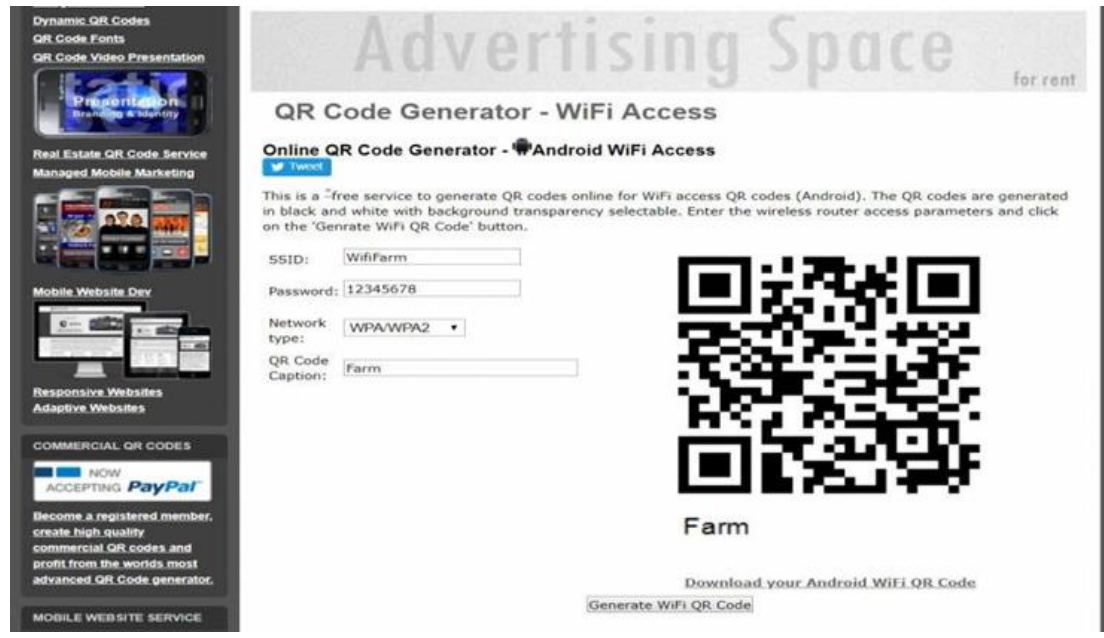

Figure 3. QR code Generation for Wi-Fi access

\subsection{QR code signs for plants}

In front of each plant, there is a QR code sticker that includes ID for the plant [17]. When the customer scans this code, he can get all related information of the plant [18]. The QR codes for the plants can be generated easily from a free online website by inserting plant data (ID) for each sample, then this website generates QR code for a specific plant. The QR code can be downloaded as a JPG image file [19]. Figure 4 shows the encryption of the plant ID in a QR code.

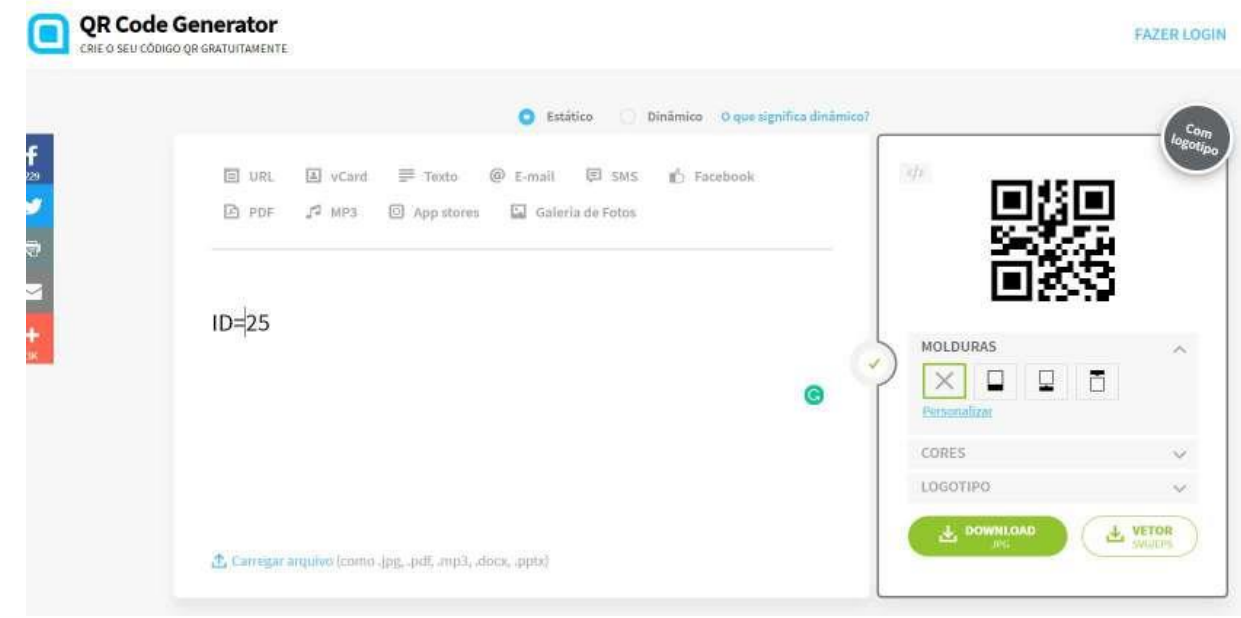

Figure 4. QR code Generation for plants

\section{RESULTS AND DESCUSSION}

A simple prototype can be implemented for the proposed system, which covers a small zone of a farm, using one Router as well as need to hardware and software requirements[20]. The hardware includes 
HP laptop, TP-LINK router, and smartphone Galaxy s8. Moreover, the software contains Android studio platform in this system 3.4.1version is used with some of library implementation in Gradle file [21], such as (zxing:core:3.2.1 [22], volley:1.1.1 [23], picasso:2.5.2 [24], etc) and AppServ simple package for programming consist of (Apache, PHP, and MySQL) [25]. To run the proposed application firstly the mobile smartphone must be connected to the farm Wi-Fi network that is available on farm zone only. The client uses the mobile phone's camera to scan QR code for Wi-Fi network access. If the wrong QR code is read, a message is displayed to the visitor (error in connection). Otherwise, a message appears on the visitor's phone (connection successfully). Figure (5) shows this process.

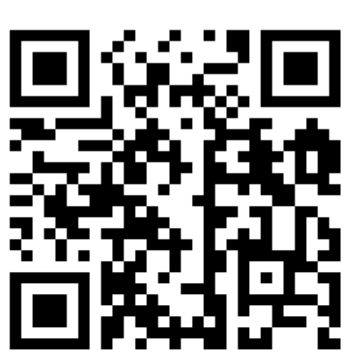

WiFi Farm

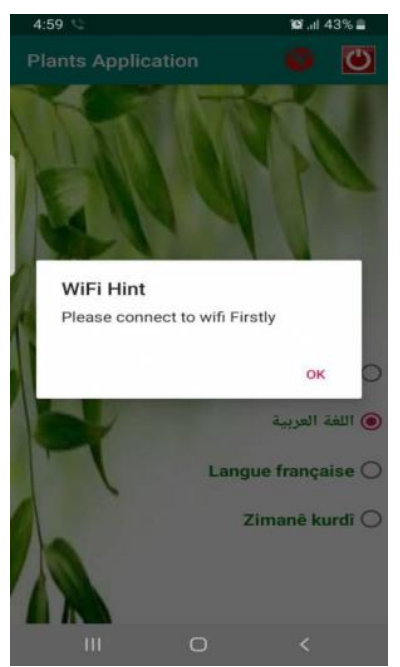

(b)

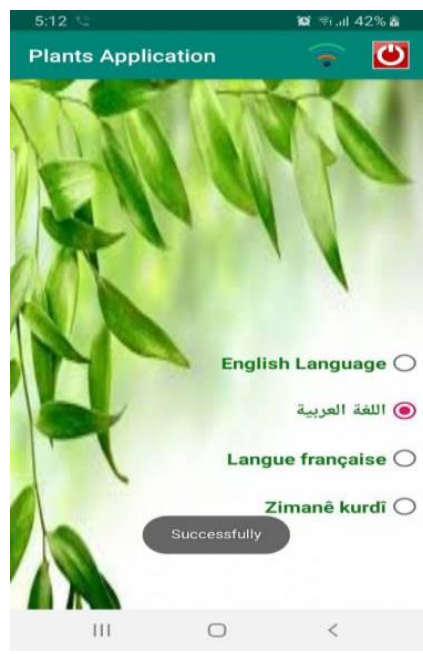

(c)

Figure 5. connecting to Wi-Fi farm. (a) QR codes for farm Wi-Fi, (b) Wi-Fi not connected, (c) Successfully connected

After connection is performed, the mobile application is run and scan QR codes poster on plants. Then, the information embedded in the QR code, displayed on the visitor's mobile phone, is sent to the main server as a request. The main server responses the request by sending plant information to the visitor's mobile phone. These information includes in the QR code is the plant ID but the full details of this plant are based on that ID stored in the database exist on farm's server. If the plant ID does not exist in the database, there is no answer from the server for that wrong ID that embedded in QR. Figure 6 illustrates this process.

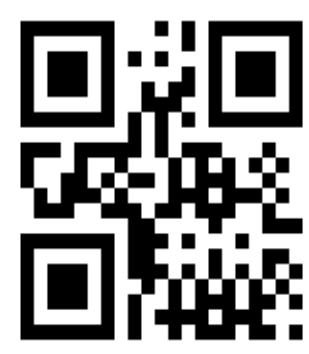

(a)
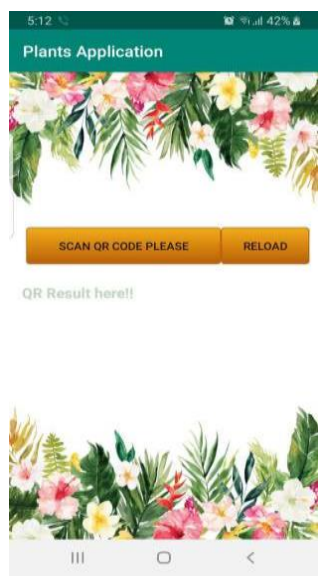

(b)

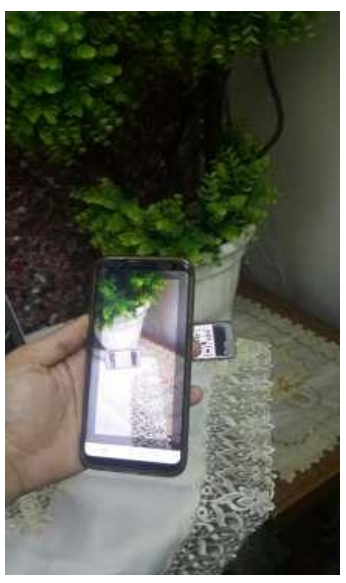

(c) 


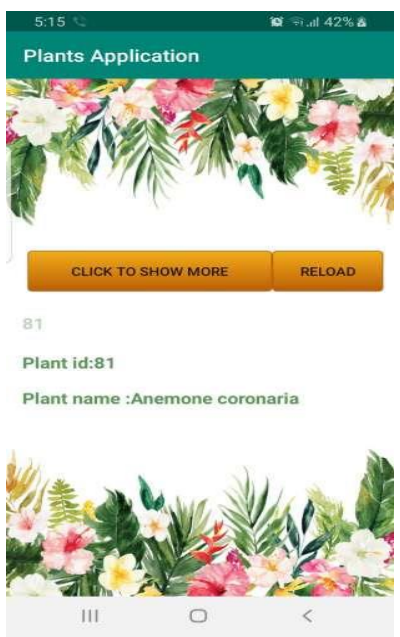

(d)

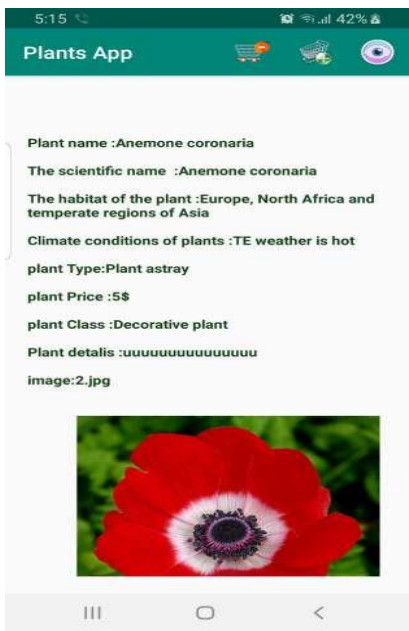

(e)

Figure 6. Scanning QR and retrieving plants information, (a) Example QR code for Plant, (b) Press to scan

QR code, (c) Scan QR tag on plant, (d) More details about the plant, (e) shows details about the plant

The visitor can add the plants that desire to buy in cart after inserting how many items needed. In case of entering a wrong plant into cart or customer retreat for purchasing the plant, it can be deleted from the shopping cart directly by pressing the pull of the cart button. In addition, the customer can view all the contents of the shopping cart and the total price for purchasing by pressing on the show (eye) button. Also, the visitor can select some or all cart contents for buying or delete the plant not interested in it. and can add other items to cart if he desires. Figure 7 shows how to use the cart.

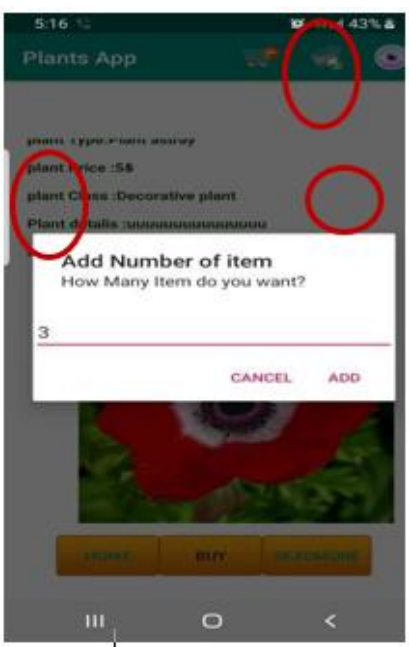

(a)

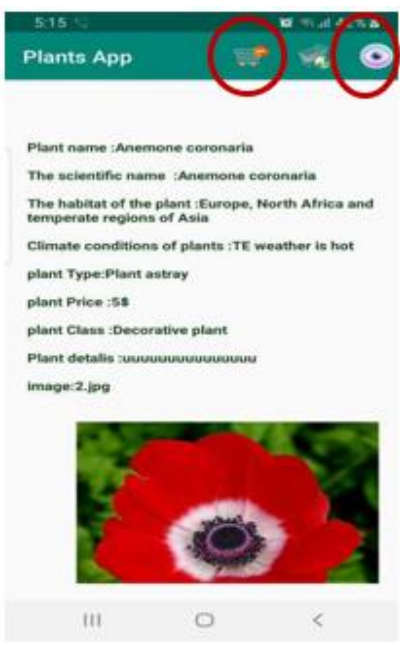

(b)

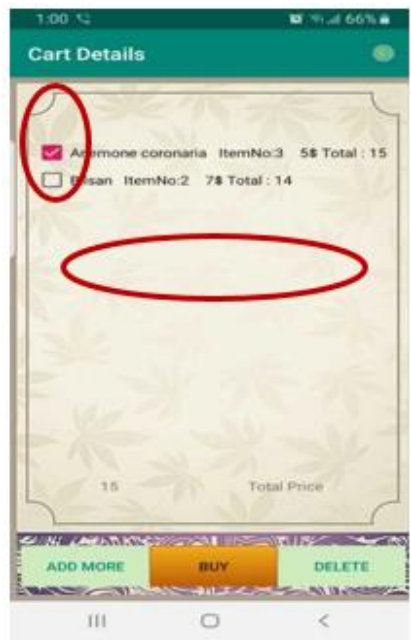

(c)

Figure 7. Processes in the shopping cart. (a) add to cart, (b) pull from the cart, (c) Select items for buy or delete with the total price

When the visitor decides go to sale process, he must be registered in the system by recorded some related information, such as (name, phone number, bank account and etc.). The MAC address can be achieved automatically after pressing on the register button. If the visitor already has an account, he needs only enter name and password, otherwise he must register in the system. So that, the authenticity of the information is confirmed. The customer gets ID only if interested to buy. This method helps to reduce the consumption of storage space and overload on the server, as not all visitors are registered once they enter the network. Login and registration is shown in Figure 8. 


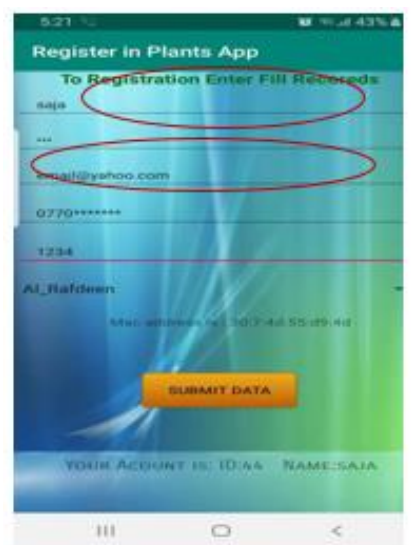

(a)

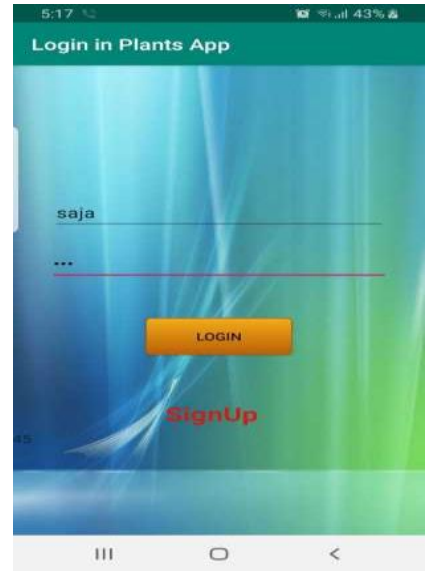

(b)

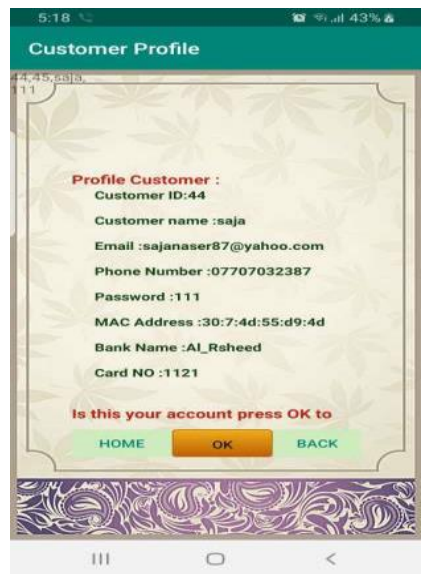

(c)

Figure 8. Customer registration, profile and login. (a) Register with MAC and customer has ID, (b) Login page, (c) Customer profile

After that, the application allows the customer to identify if delivery service is wanted by select one of choice (Yes or No). If the customer chooses that service, an additional cost of using this service is added to the total price. Then, the location address must be entered, the place he wants. Otherwise, the total cost appears only, see Figure (9).

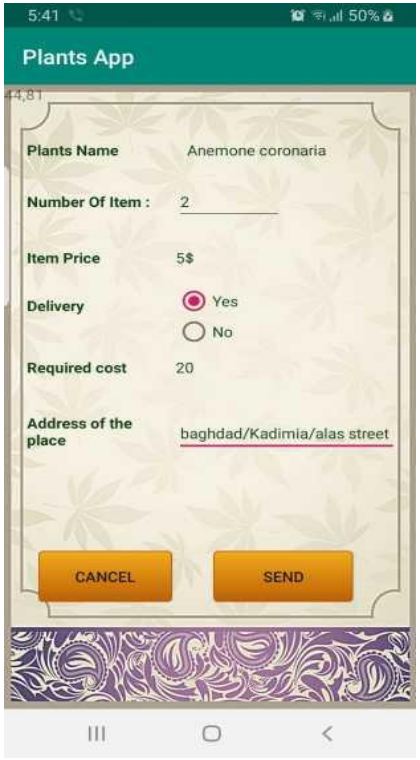

(a)

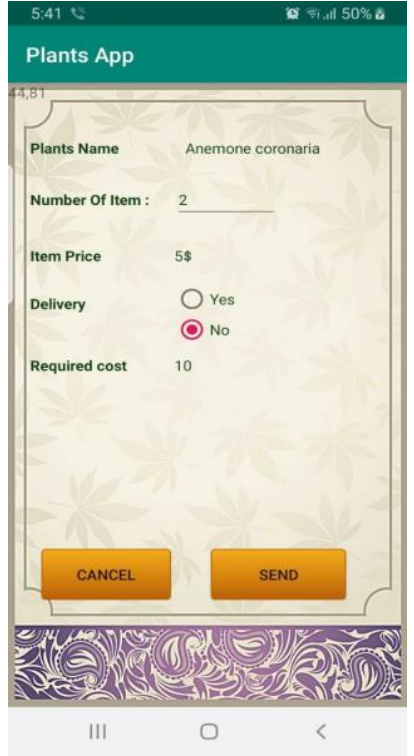

(b)

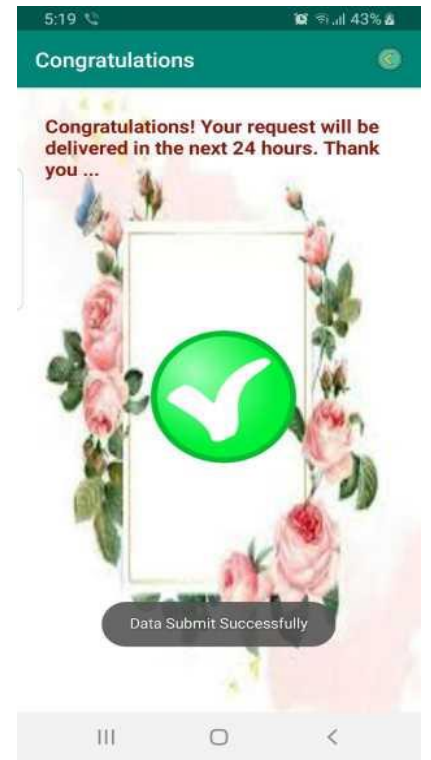

(c)

Figure 9. Choose delivery service. (a) Choose delivery service, (b). Without delivery service,

(c) Send order successfully

\section{CONCLUSION}

A mobile application, called plant system was proposed for a plant's shop that contains many services provided to the visitor, such as (identification for plants, details of a special plant, buying of plants, etc.). QR code was used for plant identifier, as it is a modern and effective technique, used to encode a large amount of data and decrypt it very quickly. The proposed system can act as a guide at the shop. So that, each visitor on the farm has his own electronic guide. When the customer needs to know details about a particular plant such as (name of the plant, suitable soil, climatic conditions, shade or light plant, plant price, etc.) or any other information about plants. The visitor needs his mobile phone to read the QR code attached to 
the plant, where short or complete information about the plant is retrieved from the database stored on the farm's main server to the customer's mobile screen. The proposed system includes two sides: server and client. The server included the main software used for storing information and managing the sale systems. The client (mobile application) used an interface application to utilize the application in an easy way. The obtained results showed that the proposed system is performed in efficient performance.

\section{REFERENCES}

[1] S. Tiwari, "An introduction to QR code technology," Proc. - 2016 15th Int. Conf. Inf. Technol. ICIT 2016, vol. 1, pp. 39-44, 2017.

[2] O. Lopez-Rincon, O. Starostenko, V. Alarcon-Aquino, and J. C. Galan-Hernandez, "Binary Large Object-Based Approach for QR Code Detection in Uncontrolled Environments,” J. Electr. Comput. Eng., vol. 2017, pp. 15, 2017.

[3] K. Czuszynski and J. Ruminski, "Interaction with medical data using QR-codes," in 2014 7th International Conference on Human System Interactions (HSI), pp. 182-187, 2014.

[4] P. K. Jithin, M. Vishnuram, P. Prasath, and J. T. Thirukrishna, "Tourism Guide for Tamilnadu ( Android Application )," Int. J. Innov. Res. Sci. Technol., vol. 4, no. 11, pp. 112-116, 2018.

[5] F. Masalha, "A Students Attendance System Using QR Code," Int. J. Adv. Comput. Sci. Appl., vol. 5, no. 3, pp. 75-79, 2014.

[6] N. FatihahSahidan, A. K. Juha, N. Mohammad, and Z. Ibrahim, "Flower and leaf recognition for plant identification using convolutional neural network," Indones. J. Electr. Eng. Comput. Sci., vol. 16, no. 2, pp. 737-743, 2019.

[7] B. M. Silva, I. M. Lopes, M. B. Marques, J. J. P. C. Rodrigues, and M. L. P. Jr, "A Mobile Health Application for Outpatients Medication Management," in IEEE International Conference on Communications (ICC), pp. 4389-4393, 2013.

[8] D. Jagodi, D. Vuji, and S. Ran, “Android system for identification of objects based on QR code," Telecommun. Forum Telfor, vol. 7, pp. 922-925, 2015.

[9] M. V Dahigonde and V. J. Kadam, "QR Code Based Digitized Marksheet System," Int. J. Res. Comput. Sci. Inf. Technol., vol. 2, no. 2, pp. 120-123, 2014.

[10] B. Ahmed and S. Al-qaraawi, "Design and Implementation of e-Shopping System Using QR Code and Smart Mobile Phone," Iraqi J. Comput. Commun. Control Syst. Eng., vol. 19, no. 3, pp. 56-64, 2019.

[11] B. Ahmed and S. Al-Qaraawi, "Design and Implementation Guidance Mobile Application 1 1,2," Int. J. ofAdvanced Res. Comput. Eng. Technol., vol. 8, no. 7, pp. 283-290, 2019.

[12] S. Haque and R. Dybowski, “Advanced QR Code Based Identity Card : A New Era for Generating Student ID Card in Developing Countries," in International Conference on Systems Informatics, Modelling and Simulation, pp. 76-82, 2014.

[13] S. L. Fong, F. Y. H. Ahmed, and A. Jamal, "Smart City Bus Application with Quick Response ( QR ) Code Payment," in International Conference on Software and Computer Applications, vol. 2, pp. 248-252, 2019.

[14] A. Cornelia and A. Repanovici, "Legal Information Management Using QR Codes," Qual. Quant. Methods Libr., vol. 4, pp. 381-397, 2015.

[15] K. L. Tan and K. C. Lim, "Fast surveillance video indexing \& retrieval with WiFi MAC address tagging," Indones. J. Electr. Eng. Comput. Sci., vol. 16, no. 1, pp. 473-481, 2019.

[16] “QR Code Generator WiFi Access.” [Online]. Available: https://blog.qr4.nl/QR-Code-WiFi.aspx. [Accessed: 30Aug-2019].

[17] S. A. Case, D. Bosco, C. Central, A. Pradesh, S. C. Singha, and M. K. Verma, "Integration of AIDC Technology in Mobile via QR Code for Enhancing the Library Integration of AIDC Technology in Mobile via QR Code for Enhancing the Library Services : A Case Study of Don Bosco College Central Library, Arunachal Pradesh," Indian J. Inf. Sources Serv., vol. 9, no. 2, pp. 44-48, 2019.

[18] C. Hema, S. Sankar, and M. Sandhya, "Tag count based priority scheduling algorithm for mitigating the RFID collisions,” Indones. J. Electr. Eng. Comput. Sci., vol. 18, no. 1, pp. 434-442, 2019.

[19] "Gerador de código QR - Crie aqui códigos QR gratuitos." [Online]. Available: https://br.qr-code-generator.com/. [Accessed: 30-Aug-2019].

[20] R. Ramly, A. A. B. Sajak, and M. Rashid, "IoT recycle management system to support green city initiatives," Indones. J. Electr. Eng. Comput. Sci., vol. 15, no. 2, pp. 1037-1045, 2019.

[21] "Download Android Studio and SDK tools | Android Developers." [Online]. Available: https://developer.android.com/studio/. [Accessed: 30-Aug-2019].

[22] "GitHub - zxing/zxing: ZXing ('Zebra Crossing') barcode scanning library for Java, Android.” [Online]. Available: https://github.com/zxing/zxing. [Accessed: 13-Sep-2019].

[23] "Volley overview | Android Developers." [Online]. Available: https://developer.android.com/training/volley. [Accessed: 12-Jan-2020].

[24] "Picasso." [Online]. Available: https://square.github.io/picasso/. [Accessed: 12-Jan-2020].

[25] "AppServ: Apache + PHP + MYSQL - AppServ, AppServHosting, AppServNetwork, AppServ Download." [Online]. Available: https://www.appserv.org/en/. [Accessed: 30-Aug-2019]. 